\title{
Grounding and the Myth of Ontological Innocence
}

Forthcoming in Australasian Journal of Philosophy

(Please cite published version)

\section{Introduction}

Jonathan Schaffer [2009: 353] writes:

... Armstrong makes crucial use of the notion of 'the ontological free lunch': "[W]hatever supervenes... is not something ontologically additional to the subvenient, or necessitating, entity or entities. What supervenes is no addition to being." [I]n Aristotelian terms, there is a straightforward way to understand Armstrong: whatever is dependent is not fundamental, and thus no addition to the sparse basis. Thus, Armstrong's notion of an ontological free lunch seems best understood against an Aristotelian background.

More recently, Schaffer [2014: 647-8] elaborates:

...[D]erivative entities are an 'ontological free lunch', in the sense that they are genuinely new and distinct entities but they cost nothing by measure of economy.... Derivative entities are additional commitments, but they cost nothing. More precisely: derivative entities cost nothing further, beyond the cost incurred for positing their fundamental grounds.

For Schaffer, grounded entities are an "ontological free lunch"-that is, they are ontologically innocent-because ontological commitment to a grounded entity costs nothing more by way of theoretical parsimony or economy than the cost of ontological commitment to their fundamental grounds. ${ }^{1}$

Ross Cameron [2014: 100] says:

Derivative entities don't lack being, but their being is inherited from their grounds, and so... acknowledging that there are these things incurs no further ontological commitment over acknowledging their ultimate grounds.

\footnotetext{
${ }^{1}$ Bennett [2017: 192_-196] and Bennett [2011: 32] defends a similar view.
} 
Cameron's understanding of the ontological innocence of the grounded is even stronger than Schaffer's. Ontological commitment to a grounded entity, for Cameron, is not even an additional commitment over and above the commitments one incurs by acknowledging that entity's ultimate grounds.

Kit Fine [2001: 15] claims that the grounded "consists in nothing more than" its grounds.

Fine [2012: 39] explains this claim as follows:

...[A]11 that is properly implied by the statement of (metaphysical) ground itself is that there is no stricter or fuller account of that in virtue of which the [grounded] holds. If there is a gap between the grounds and what is grounded, then it is not an explanatory gap.

So, for Fine, that the grounded consists in nothing more than its grounds is a matter of there being no "explanatory gap" between the grounds and the grounded.

Suppose that $\mathrm{x}$ exists and that $\mathrm{y}$ exists. And consider the conjunctive fact that $\mathrm{x}$ and $\mathrm{y}$ exist. The conjunctive fact that $\mathrm{x}$ and $\mathrm{y}$ exist is partially grounded in the fact that $\mathrm{x}$ exists. But that conjunctive fact is fully grounded in two facts, taken together: the fact that $\mathrm{x}$ exists and the fact that y exists. Presumably Schaffer, Cameron, and Fine are not claiming that grounded entities are ontologically innocent relative to their mere partial grounds alone. Instead, I take them to agree that grounded entities are ontologically innocent relative to their full grounds.

Thus I take Schaffer, Cameron, and Fine — along with many other defenders of grounding, including Bennett [2017], Inman [2014], and Jenkins [2011]— to endorse the following thesis:

The Ontological Innocence Thesis (OIT): necessarily, for any $\mathrm{x}$ and $\mathrm{y}$, if $\mathrm{x}$ is fully grounded in $\mathrm{y}$ then $\mathrm{x}$ is ontologically innocent relative to $\mathrm{y}{ }^{2}$

\footnotetext{
${ }^{2}$ Although, for dissent, see deRosset [2010], Audi [2012], and Turner [2016].
} 
Most of OIT's defenders, with Fine [2012] as a notable exception, assume that entities of various ontological categories - ex. particulars, worldly facts, etc. — can be the relata of grounding (see Schaffer [2009] and [2014], Cameron [2008], and Bennett [2017]). ${ }^{3}$ My formulation of OIT makes the same assumption. So does the central argument of this paper.

This paper's main conclusion is that OIT is false. My argument is a reductio. Here is its first premise:

(1) OIT is true.

The notion of groundmates, two or more numerically distinct grounded entities sharing at least one of their full grounds, plays a key role in the rest of my argument. I shall argue that if OIT is true then there are groundmates (Sections 2 and 3). However, I will also argue that OIT is true only if there are no groundmates (Sections 3 and 5). Thus, so I shall conclude, OIT entails a contradiction. Therefore, OIT is false (Section 5).

Moreover, in seeing why OIT is false, we will be left with three surprising options. Either there are fundamental facts about grounded entities, in which case the orthodox "purity" constraint on fundamental reality is false, or else one of two versions of "flatworldism," according to which everything is fundamental, is true (Section 6). So this paper's second conclusion is that, once advocates of metaphysical grounding have discarded OIT, they are in for yet another surprise.

\section{Permissivism}

Consider the following three propositions:

\footnotetext{
${ }^{3}$ For discussion of entity grounding vs fact grounding, see Correia and Schneider [2014].
} 
(a) Entity e exists.

(b) If the set $\{\mathrm{e}\}$ exists, then $\{\mathrm{e}\}$ is fully grounded in entity e.

(c) The set $\{e\}$ exists.

Suppose you accept (a) and (b). Add that you also endorse OIT. And suppose you infer from (a), (b), and OIT that, if $\{\mathrm{e}\}$ exists, then $\{\mathrm{e}\}$ is ontologically innocent relative to entity e. Then, regardless of which account of ontological innocence you endorse, you have no good parsimonybased reason not to accept (c) as well.

For example, suppose you accept Cameron's account. Then you believe that no ontological commitment you would incur by postulating $\{\mathrm{e}\}$ would be a distinct, additional commitment over and above however many commitments you have already incurred by postulating entity e. Indeed, the commitments you would incur by postulating $\{\mathrm{e}\}$ just are one or more of the very commitments you already have.

Or suppose you accept Schaffer's account. Then you believe the cost of whatever ontological commitments you would incur by postulating $\{\mathrm{e}\}$ would be no addition to the total theoretical cost of whatever commitments you have already incurred and paid for by postulating entity e. Indeed, the price of the commitments you would incur by postulating $\{\mathrm{e}\}$ just is the price you have already been charged for postulating entity e.

Finally, suppose you accept Fine's account. Then you believe that, if $\{\mathrm{e}\}$ exists, then there is no explanatory gap between $\{\mathrm{e}\}$ and entity e. Plausibly, there is no explanatory gap between one entity and another only if every fact about the former is ultimately metaphysically explicable in terms of facts exclusively about the latter. 
Thus, given Fine's account, you can infer that, if $\{\mathrm{e}\}$ exists, then every fact about $\{\mathrm{e}\}$ is ultimately metaphysically explicable in terms of facts about entity e. You already believe that entity e exists. So you can infer that, if $\{\mathrm{e}\}$ exists, then there are be no brute facts whatsoever about $\{\mathrm{e}\}$.

Indeed, once you accept (a), (b), and OIT, then you do not have any other sort of reason not to accept (c). For you already believe that entity e exists. As a result, you have a good reason not to accept (c) only if you can identify some difference between entity e and $\{\mathrm{e}\}$ that justifies your inclusion of the former but not the latter in your ontology. In other words, you must identify an ontologically significant difference between entity e and $\{e\} .^{4}$

However, if there were an ontologically significant difference between entity e and $\{\mathrm{e}\}$, then $\{\mathrm{e}\}$ would thereby be a genuine "addition to being" over and above entity e. But you believe that, if $\{e\}$ exists, $\{e\}$ is ontologically innocent relative to entity e. Thus, you should conclude that there are no such differences between $\{e\}$ and entity e. Therefore, you have no good reason not to accept (c).

Consider a specific allegedly ontologically significant difference between entity e and $\{e\}$. For example, suppose that some concrete entity c has causal powers. Add that, if abstract entity a exists, then a is essentially causally inert. And suppose that the Eleatic "mark" or criterion of existence is true: no existing entity is causally inert. Given everything we have supposed, it should be clear that there is an ontologically significant difference between concrete entity c and abstract entity a-a difference with respect to whether they have any causal powers.

However, note that something else follows about concrete entity c and abstract entity a. For, in general, no essentially causally inert entity is ontologically innocent relative to any entity

\footnotetext{
4 The phrase "ontologically significant difference" is inspired by Korman [2010]'s formulation of arbitrariness arguments against conservative views in the metaphysics of material objects.
} 
that has causal powers. Conversely, no entity that has causal powers is ontologically innocent relative to any entity that is causally inert. It follows that, if abstract entity a exists, then abstract entity a is not ontologically innocent relative to concrete entity c.

Now, you believe that, if $\{e\}$ exists, then $\{e\}$ is ontologically innocent relative to entity e. Suppose you are correct. Then, if $\{\mathrm{e}\}$ exists, $\{\mathrm{e}\}$ is essentially causally inert if and only if entity e is essentially causally inert. Entity e is not essentially causally inert. So, if $\{e\}$ exists, then $\{e\}$ is not essentially causally inert either. ${ }^{5}$ Therefore, entity e and $\{e\}$ do not differ in this ontologically significant respect.

The same reasoning goes, mutatis mutandis for other potential ontologically significant differences between entity e and $\{\mathrm{e}\}$. I conclude that you have no good reason not to postulate $\{\mathrm{e}\}$. You should go ahead and do so.

Consider the following generalized versions of (a), (b), and (c), respectively:

Existential A: There are some Fs.

Grounding Bridge: If there are any Gs, then the Gs are fully grounded in the Fs.

Existential B: There are some Gs.

According to permissivism, anyone who believes both an instance of Existential A and a corresponding instance of Grounding Bridge should also believe the relevant instance of

\footnotetext{
${ }^{5}$ Let an epistemic reason for not accepting (c) be any reason that turns on the claim that, even if $\{\mathrm{e}\}$ exists, no one could ever know that $\{\mathrm{e}\}$ exists. However, such a thesis about the alleged unknowability of some entity itself presumably relies upon the metaphysical thesis that, if $\{\mathrm{e}\}$ exists, $\{\mathrm{e}\}$ is essentially causally inert and thus incapable of causing anyone to believe that $\{\mathrm{e}\}$ exists. But I have just argued that OIT's defenders who accept (a) and (b) must deny that, if $\{\mathrm{e}\}$ exists, then $\{\mathrm{e}\}$ is causally inert. Therefore, no such defenders of OIT have any epistemic reason not to postulate $\{\mathrm{e}\}$ either. See Barker [2019] for relevant discussion.
} 
Existential B. ${ }^{6}$ For example, anyone who believes that there are some xs arranged table-wise, and who also believes that if there are tables then tables are fully grounded in some things arranged table-wise, should also believe that there are tables.

Most of OIT's defenders-e.g. Bennett [2017], Cameron [2008], Fine [2009], Inman [2014], Schaffer [2009], and Schaffer [2014] — are permissivists. This is no accident. For any defender of OIT who also believes that Existential A has an instance and who also accepts the corresponding instance of Grounding Bridge has no good reason not to believe the corresponding instance of Existential B. So she ought to do so. ${ }^{7}$

\section{Property Fixing}

Consider the following thesis:

Property Fixing Thesis (PFT): if some entity $\mathrm{x}$ has some qualitative property $\mathrm{F}$ and $\mathrm{x}$ is fully grounded in some entity y and y has qualitative properties G1... Gn then, necessarily, for any entity $z$, if $z$ is fully grounded in $y$ and $y$ has G1...Gn then $z$ is F.

\footnotetext{
${ }^{6}$ Permissivists tend to restrict their ontological profligacy to entities with logically consistent modal profiles. Perhaps you find this restriction objectionably ad hoc or otherwise unmotivated. However, that is no objection to this paper's reductio argument against OIT. For anyone who accepts OIT should also accept permissivism. As a result, if permissivism leads to contradictions of its own, then we have an abundance of other reductio arguments against OIT. Let a thousand reductios bloom! Thanks to Dan Korman for this objection.

${ }^{7}$ As the arguments of Section 4 will show, the permissivist who believes that both Existential and Bridge have a variety of instances will thereby be committed to abundantly many types and tokens of grounded entities. Such an ontology is, at the very least, quantitatively unparsimonious. Thus, if the lack of quantitative parsimony is a theoretical vice, then Section 2's argument alone gives us a serious objection to OIT (see Nolan [1997]). However, OIT's defenders should deny that quantitative parsimony simpliciter is a theoretical virtue. For, according to OIT, a theory $\mathrm{T}$ is made less quantitatively parsimonious only to the extent that $\mathrm{T}$ postulates more fundamental entities than necessary (eg. Schaffer [2014]). So Section 2's argument that OIT's defenders should be permissivists may not, all by itself, raise any insurmountable problems for OIT. Thanks to an anonymous referee for raising this point.
} 
Intuitively, PFT says that any two possible entities that are indiscernible with respect to at least one of their full grounds are also qualitatively indiscernibility.

Here is Premise 2:

(2) If OIT is true then PFT is true.

My defense of Premise 2 involves the following thesis:

Purity: there are no fundamental facts about any grounded entity. ${ }^{8}$

Thus, where entity $\mathrm{x}$ is a grounded entity, Purity prohibits there from being any fundamental facts about $\mathrm{x}$. A fact is fundamental, let us say, just in case it has no metaphysical explanation in terms of any other facts. For example, a fundamental fact cannot be metaphysically reduced to any other fact or facts. Nor does a fundamental fact have a "real definition" in terms of other facts. Nor are they metaphysically grounded in any other facts. And so on.

I shall defend the following two conditionals:

(2.1) If PFT is false then Purity is false.

(2.2) If Purity is false then OIT is false.

${ }^{8}$ Sider [2011: 105-6] originally formulated a purity principle in terms of linguistic entities like "truths" and "notions," which he takes to be the primary bearers of fundamentality and derivativeness: "fundamental truths involve only fundamental notions." This paper's Purity principle, like deRosset [2013]'s similar CORR principle, is the worldly analogue of Sider's purity principle. 
2.1 and 2.2 together imply a third conditional:

(2.3) If PFT is false then OIT is false.

2.3 is just Premise 2's contrapositive. So, once I have defended 2.1 and 2.2, I will have thereby defended the truth of Premise 2.

Here is my defense of 2.1. Begin by assuming that PFT is false. That is, assume that there is some arbitrary grounded entity $\mathrm{x}$ that has some qualitative property $\mathrm{F}$, that $\mathrm{x}$ is fully grounded in some entity $y$, that $y$ has qualitative properties G1...Gn, and that the following is nevertheless possible: entity y exists, y has qualitative properties G1...Gn, y fully grounds some entity z, and yet grounded entity $\mathrm{z}$ is not $\mathrm{F}$.

Now, the fact that grounded entity $\mathrm{x}$ is $\mathrm{F}$ is either a fundamental fact or else it is metaphysically explained in terms of some other facts. If grounded entity $\mathrm{x}$ 's being $\mathrm{F}$ is fundamental, then there is at least one fundamental fact about grounded entity x. Therefore, Purity is false.

On the other hand, if grounded entity x's being F is metaphysically explained, then only certain kinds of facts can metaphysically explain x's being F. For example, x's being F is not metaphysically explained by x's being fully grounded in entity y. To see why, note that if x's being F were metaphysically explained by x's being fully grounded in $\mathrm{y}$, then, necessarily, any possible entity $\mathrm{z}$ that is fully grounded in y would also be F. However, in assuming that PFT is false, we have assumed that there is some possible entity $\mathrm{z}$ that is fully grounded in $\mathrm{y}$ and yet is not F.

Indeed, analogous reasoning shows that x's being F is not metaphysically explained by x's being fully grounded in entity y together with y's having qualitative properties G1...Gn. After all, 
we have assumed that, possibly, there is some entity $\mathrm{z}$ such that $\mathrm{z}$ is not $\mathrm{F}$ and yet $\mathrm{z}$ is fully grounded in $\mathrm{y}$ and $\mathrm{y}$ has qualitative properties $\mathrm{G} 1 \ldots \mathrm{Gn}$.

Here is the more general lesson about what kinds of facts can and cannot metaphysically explain grounded entity x's being F. Let us say that, if grounded entity x has some property $\phi$ that possible entity z lacks, then grounded entity x's being $\phi$ is a $z$-individuating fact about grounded entity $\mathrm{x}$. Where a fact $[\mathrm{p}]$ is a z-individuating fact about grounded entity $\mathrm{x},[\mathrm{p}]$ is metaphysically explained by some collection of facts, $\Delta$, only if $\Delta$ are also z-individuating facts about grounded entity x. Equivalently: z-individuating facts can only be metaphysically explained by other zindividuating facts.

Grounded entity x's being F is a z-individuating fact about $\mathrm{x}$, while grounded entity x's being fully grounded in y is not. That is why the latter cannot serve to metaphysically explain the former.

But perhaps there is some other $\mathrm{z}$-individuating fact(s) about grounded entity $\mathrm{x}$ that can serve to metaphysically explain x's being F. For example, suppose that grounded entity $x$ has the kind-membership property of being a set, but that possible entity $\mathrm{z}$ is not a set. Then, perhaps, grounded entity x's being $F$ is metaphysically explained by x's being a set.

Of course, grounded entity x's being a set is itself is either a fundamental fact or else it is metaphysically explained. If the former, then Purity is false. If the latter, then there must be some further z-individuating fact(s) that metaphysically explains the fact that grounded entity $\mathrm{x}$ is a set. For example, perhaps a specific "building" fact about grounded entity $\mathrm{x}$, ex. the fact that $\mathrm{x}$ has members, is both z-individuating and metaphysically explains x's being a set (see Bennett [2017] on building facts). 
Of course, $x$ 's having members is itself either fundamental or metaphysically explained by some still further z-individuating fact about grounded entity x. And so on for each subsequent zindividuating fact.

Now let "series S" be the complete collection of every z-individuating fact about grounded entity $\mathrm{x}$, beginning with the fact that $\mathrm{x}$ is F. Series $\mathrm{S}$ is either finite in length, or series $\mathrm{S}$ is infinitely long. Either way, Purity is false.

To see this, first suppose that series $S$ is finite in length. Then there is a final z-individuating fact(s) about grounded entity $\mathrm{x},[\mathrm{p}]$, such that $[\mathrm{p}]$ ultimately metaphysically explains every other z-individuating fact in series S. Metaphysical explanation is asymmetric. Thus, [p] is itself not metaphysically explained by any other fact in series S. However, series S contains every zindividuating fact about grounded entity $\mathrm{x}$. So [p] is not metaphysically explained by any other zindividuating fact about grounded entity x. So [p] is not metaphysically explained by any facts at all. Thus, $[\mathrm{p}]$ is fundamental. Purity is false.

Suppose instead that there are infinitely many facts in series $S$, i.e. that series $S$ is an "infinitely descending" chain of metaphysical explanation such that, for any z-individuating fact [p] in series $\mathrm{S}$, there are some other $\mathrm{z}$-individuating fact(s) in series $\mathrm{S}$ that metaphysically explains $[\mathrm{p}]$.

Following Dixon [2016: 446], I shall assume that metaphysical explanation is well-founded in the following weak sense:

Well-Founded (WF): Every non-fundamental fact $[\mathrm{p}]$ is ultimately metaphysically explained by some fundamental facts, $\Delta .{ }^{9}$

\footnotetext{
${ }^{9}$ Note that Dixon's original formulation is in terms of full ground.
} 
As Dixon points out, WF, unlike stronger formulations of well-foundedness, is compatible with infinitely descending chains of metaphysical explanation. As a result, in assuming the truth of WF, I am not thereby making the more controversial assumption that every chain of ground or metaphysical explanation must eventually terminate (see Dixon [2016: 450]).

Each of the infinitely many z-individuating facts in series $S$ facts, by hypothesis, is metaphysically explained by another non-fundamental z-individuating fact in series S. Given WF, however, each of these infinitely many z-individuating facts must also be ultimately metaphysically explained by some fundamental fact or facts. ${ }^{10}$

Now, z-individuating facts about grounded entity x can only be metaphysically explained by other z-individuating facts. So the fundamental fact(s) that metaphysically explains each of infinitely many $\mathrm{z}$-individuating facts in series $\mathrm{S}$ must itself be a $\mathrm{z}$-individuating fact about grounded entity $\mathrm{x}$. Thus, there is at least one fundamental z-individuating fact(s) about grounded entity $\mathrm{x},[\mathrm{p}]$. So there is at least one fundamental fact about grounded entity x. Purity is false.

To sum up: if PFT is false then there is a series $\mathrm{S}$ of $\mathrm{z}$-individuating facts about grounded entity x. Series $S$ is either finite or infinite. If $S$ is finite, then Purity is false. If $S$ is infinite, then Purity is false. Thus, if PFT is false then Purity is false. By contraposition, Premise 2.1 is true.

Here is my defense of 2.2. Begin by supposing that some grounded entity violates Purity. For example, suppose that entity $\mathrm{x}$ is fully grounded in $\mathrm{y}$, that $\mathrm{x}$ is $\mathrm{F}$, and that $\mathrm{x}$ 's being $\mathrm{F}$ is a fundamental fact about $\mathrm{x}$. There are three reasons to conclude that grounded entity $\mathrm{x}$ is not ontologically innocent relative to its full grounds, entity y.

\footnotetext{
10 This is a case of explanatory overdetermination.
} 
First, anyone who postulates grounded entity $\mathrm{x}$ is thereby committed to grounded entity x's being F. That is a fundamental fact about grounded entity $\mathrm{x}$. Therefore, anyone who postulates grounded entity $\mathrm{x}$ is thereby committed to at least one fundamental fact about grounded entity $\mathrm{x}$. It is uncontroversial that ontological commitment to a fundamental fact is both an additional and additionally costly commitment over and above the number and costs of any other commitments one already has.

So, in this case, commitment to the fundamental fact that $\mathrm{x}$ is $\mathrm{F}$ is both an additional and additionally costly commitment over and above the number and costs of commitments incurred by postulating x's putative full grounds, entity y. Therefore-if ontological innocence is a matter of either the number or costs of one's ontological commitments-grounded entity $\mathrm{x}$ is not ontologically innocent relative to its full grounds, entity y.

Second, if there is a fundamental-i.e. metaphysically inexplicable—fact about some entity $\mathrm{x}$, then there is an "explanatory gap" between that entity and every other entity (see Section 2). We are supposing that there is at least one fundamental fact about grounded entity $\mathrm{x}$. Thus, there is an explanatory gap between grounded entity $\mathrm{x}$ and its full grounds, entity $\mathrm{y}$. Thereforeif ontological innocence is a matter of there being no explanatory gaps-grounded entity $\mathrm{x}$ is not ontologically innocent relative to its full grounds.

Third, consider the metaphorical "book of the world," the book detailing each and every fundamental fact and nothing else (see Sider [2011]). Any entity that the book's author must mention by name before the book can be completed is a genuine "addition to being." The ontologically innocent entities, by contrast, are those entities the book's author need not mention by name to finish her work. 
Grounded entity x's being F is a fundamental fact. As a result, before the book of the world can be completed, its author must write a sentence saying that x's being $\mathrm{F}$ obtains. As a result, even once the book's author pens a sentence saying that entity y exists, her work will not be completed until she mentions grounded entity $\mathrm{x}$ by name. Therefore, grounded entity $\mathrm{x}$ is not ontologically innocent relative to any other entities including its full grounds, entity y.

If Purity is false, then there is some grounded entity $\mathrm{x}$ that is not ontologically innocent relative to its full grounds. Thus, if Purity is false then OIT is false. By contraposition, Premise 2.2 is true.

Therefore, 2.3 is true. By contraposition, Premise 2 is true.

\section{Groundmates}

Let us say that entity $\mathrm{x}$ has some entity $\mathrm{z}$ as its groundmate just in case $\mathrm{x}$ is numerically distinct from $\mathrm{z}$ and there is some third entity $\mathrm{y}$ (or entities, the ys) such that $\mathrm{y}$ (or the ys) fully grounds both $\mathrm{x}$ and $\mathrm{z}$. Thus, there are groundmates if and only if some grounded entity has another as its groundmate. $^{11}$

Here is Premise 3:

(3) If OIT is true, then there are groundmates.

I shall offer three defenses of Premise 3, each of which relies in part on Section 2's conclusion that defenders of OIT should be permissivists about grounded entities.

$$
4.1 \text { Sets }
$$

\footnotetext{
${ }^{11}$ Groundmates are thus violations of Noel Saënz's Oneness principle, according to which every grounded entity has at most a single full ground [Saënz MS] Permissivism is one reason defenders of OIT cannot embrace Oneness. For another reason, see fn. 24 .
} 
If there are sets, then sets are fully grounded in the individuals that are their members. That claim is relatively uncontroversial among grounding's defenders. Indeed, the alleged grounding of sets in their members is a paradigm case of metaphysical grounding (see Fine [1995], Schaffer [2016: 53], Correia and Schneider [2012: 1], and Koslicki [2012: 188]).

Suppose you believe that if there are sets then sets are fully grounded in their members. Assume you also believe that Socrates exists. You then infer that if \{Socrates\} exists then $\{$ Socrates $\}$ is fully grounded in Socrates. Add that you accept OIT. Finally, suppose you infer from OIT and your other beliefs that if $\{$ Socrates $\}$ exists then $\{$ Socrates $\}$ is ontologically innocent relative to Socrates.

You already believe that Socrates exists. And you believe that if $\{$ Socrates $\}$ exists then \{Socrates\} is ontologically innocent relative to Socrates. As a result, you have no good reason not to believe in \{Socrates\} (see Section 2). Therefore, you should go ahead and postulate \{Socrates\}.

Now consider $\{$ Socrates $\}$ 's singleton set, $\{\{$ Socrates $\}\}$. You believe that if there are sets then they are fully grounded in their members. You accept OIT. So you should infer that if $\{\{$ Socrates $\}\}$ exists then $\{\{$ Socrates $\}\}$ is ontologically innocent relative to $\{$ Socrates $\}$, which you already believe exists. As a result, you have no good reason to withhold belief in $\{\{$ Socrates $\}\}$ (see Section 2). Therefore, you should postulate $\{\{$ Socrates $\}\}$.

You should believe that Socrates, $\{$ Socrates $\}$, and $\{\{$ Socrates $\}\}$ all exist. Moreover, since you believe that sets would be fully grounded in their members if they existed, you should believe that $\{\{$ Socrates $\}\}$ is fully grounded in $\{$ Socrates $\}$ and that $\{$ Socrates $\}$ is fully grounded in Socrates. Full grounding is transitive. So you should also believe that $\{\{$ Socrates $\}\}$ is also fully grounded in Socrates. ${ }^{12}$

\footnotetext{
${ }^{12}$ Although, see Schaffer [2010] for an argument that partial grounding is not transitive.
} 
Of course, $\{$ Socrates $\}$ and $\{\{$ Socrates $\}\}$ are numerically distinct. After all, $\{$ Socrates $\}$ has the qualitative property of having a human member, and $\{\{$ Socrates $\}\}$ has no human members. Thus, you should believe that $\{$ Socrates $\}$ and $\{\{$ Socrates $\}\}$ are numerically distinct entities and that they share at least one of their full grounds, namely, Socrates. In other words, you should believe that there are groundmates.

The above reasoning generalizes in obvious ways. Any defender of OIT who thinks that sets would be fully grounded in their members if they existed, and who already believes in some individuals, the xs, should believe that there is an infinite hierarchy of numerically distinct singleton sets: $\{\mathrm{xs}\},\{\{\mathrm{xs}\}\},\{\{\{\mathrm{xs}\}\}\}$, and so on ad infinitum. Each set in the hierarchy shares at least one full ground, namely, the xs, with every other set in the hierarchy. Any such defender of OIT should believe that there are infinitely many groundmates. ${ }^{13}$

\section{2-Complex States of Affairs}

My second defense of Premise 3 targets defenders of OIT who believe in "worldly" facts, i.e. Armstrongian state of affairs or Russellian propositions. Henceforth let a fact be an entity that is built-up out of particulars, properties, and logical connectives. For example, [ball $b$ is blue] is a worldly fact that has ball $b$ and the property of being blue as constituents.

\footnotetext{
${ }^{13}$ No defender of OIT should resist my first defense of Premise 3 by denying the transitivity of full grounding in the case of $\{\{$ Socrates $\}$ \}'s being fully grounded in $\{$ Socrates $\}$ and $\{$ Socrates\}'s being fully grounded in Socrates. For if OIT is true then $\{\{$ Socrates $\}\}$ is also fully grounded in Socrates. Suppose OIT is true. So $\{\{$ Socrates $\}\}$ is ontologically innocent relative to $\{$ Socrates\}, and $\{$ Socrates\} is ontologically innocent relative to Socrates. The ontological innocence relation itself is transitive. After all, the having the same number of commitments as relation is transitive, as is the relation of having commitments that are equally costly as relation, as is the being no explanatory gap between relation. Therefore, $\{\{$ Socrates $\}\}$ is ontologically innocent relative to Socrates. Now, presumably if some entity $\mathrm{x}$ is ontologically innocent relative to another entity $\mathrm{y}$, then there must be some underlying building relation $\mathrm{R}$ such that $\mathrm{y}$ bears $\mathrm{R}$ to $\mathrm{x}$ and it is in virtue of $\mathrm{y}$ 's bearing $\mathrm{R}$ to $\mathrm{x}$ that $\mathrm{x}$ is ontologically innocent relative to $\mathrm{y}$. To suppose otherwise would be to postulate ontologically innocence facts that "float free" of the underlying metaphysical building facts. As a result, there must be some building relation $\mathrm{R}$ such that $\{\{$ Socrates $\}\}$ bears $\mathrm{R}$ to Socrates. There are only two plausible candidates for R: set-membership and full grounding. Socrates is not a member of $\{\{$ Socrates $\}\}$. Therefore, $\{\{$ Socrates $\}\}$ is fully grounded in Socrates. Indeed, more generally, given the transitivity of the ontological innocence relation, I think the OIT ought to accept the corresponding transitivity of the full grounding relation as well.
} 
Higher-level states of affairs, such as [[ball b is blue] and [dogs bark]], are built-up via logical connectives from lower-level facts such as [ball b is blue] and [dogs bark]. Moreover, if there are any higher-level facts, then they are fully grounded in lower-level facts. Indeed, this is another paradigm case of grounding.

For example, here is Gideon Rosen [2010: 117] on the grounding of disjunctive facts:

Some of the clearest examples of grounding involve facts that stand in simple logical relations. Thus it seems quite clear that if there are disjunctive facts then a disjunctive fact is grounded in its disjuncts. If Fred is in New York then Fred is either in New York or Rome. Moreover, the fact that Fred is either in New York or Rome obtains in virtue of the fact that Fred is in New York.

Suppose you already believe that the worldly fact [Fred is in NY] exists. Suppose you also believe that if the higher-level disjunctive fact [[Fred is in NY] v [Fred is in Rome]] exists, then it is fully grounded in [Fred is in NY]. Add that you also accept OIT. Then, so you should conclude, if [[Fred is in NY] $v$ [Fred is in Rome]] exists then it is ontologically innocent relative to [Fred is in NY].

Since you already believe in [Fred is in NY], you have no good reason not to go ahead postulate the disjunctive fact [[Fred is in NY] v [Fred is in Rome]] as well. So you should do so (see Section 2). Of course, the same line of reasoning - mutatis mutandis - should lead you to postulate a mighty host of other such disjunctive facts, including [[Fred is in NY] $\mathrm{v}$ [Fred is in Paris]], and [[Fred is in NY] v [Fred is in London]], and [[Fred is in NY] v [Fred is in Seoul]], and so on.

Each of these high-level disjunctive facts has different constituents. So each of them is numerically distinct from one another. Yet, like [[Fred is in NY] v [Fred is in Rome]], each of these numerically distinct disjunctive facts is fully grounded in [Fred is in NY]. Therefore, you 
should believe that the original disjunctive fact, [[Fred is in NY] v [Fred is in Rome]], has infinitely many groundmates.

The above form of reasoning should also lead you, mutatis mutandis, to postulate other kinds of higher-level facts and thus other kinds of groundmates. For example, suppose you believe that [c is crimson] exists. Facts about the instantiation of determinable properties like the property of being red or being colored are fully grounded in facts about the instantiation of their determinates. Thus, if [c is red] and [c is colored] exist, then they are both fully grounded in [c is crimson]. You accept OIT. Thus, you should go ahead and postulate both [c is red] and [x is colored], numerically distinct higher-level facts both fully grounded in [c is crimson]. More groundmates.

You should also postulate groundmates involving existentially quantified facts, and groundmate pairs involving doubly-negated facts, and so on. And, of course, all of these types of higher-level facts can be mixed and matched in various ways to reveal still more kinds of groundmates. More generally, you should believe that any higher-level fact has at least one other higher-level fact — a disjunctive fact, an existentially quantified fact, a doubly-negated fact, etc. as its groundmate (see Section 6).

\section{3-Composite Objects}

Consider a final paradigm case of grounding: for any xs, if the xs compose an object $\mathrm{O}$, then $\mathrm{O}$ is fully grounded in the xs and how they are arranged (see See Cameron [2014], Saenz [2015], and Skiles [2015]). For example, if there is a table here, the table is fully grounded in its microphysical parts and how those parts are arranged. ${ }^{14}$

\footnotetext{
${ }^{14}$ Priority monism says the object that is the Cosmos fully grounds its composing parts, rather than vice-versa. Thus, no priority monist will accept my second defense of Premise 3. However, if priority monism is true then some grounded entity has a groundmate. The Cosmos fully grounds me. The Cosmos fully grounds you. You and I are numerically distinct. Therefore, if priority monism is true, you and I are groundmates. See Schaffer [2010a] and [2010b], and Horgan and Potrc [2012].
} 
Suppose you believe that some things, the xs, exist. And suppose you believe that, if the xs compose an object $\mathrm{O}$, then $\mathrm{O}$ is fully grounded in the xs and how they are arranged. Add that you believe OIT and infer that, if object $\mathrm{O}$ exists, then $\mathrm{O}$ is ontologically innocent relative to the $\mathrm{xs}$ and how they are arranged.

Given that you already believe that xs exist and are appropriately arranged, you have no good reason to withhold belief in object O (Section 2). So you should believe that object O exists. Of course, those xs and how they happened to be arranged were picked arbitrarily. For any ys whatsoever, and however they happen to be arranged, you should believe that there is an object composed of those ys. In other words, you should believe that composition is unrestricted.

Moreover, for every object O you postulate, OIT should lead you to postulate another, numerically distinct object O* with which O mereologically coincides (see Baker [1997] on mereological coincidence). To see this, suppose you believe in some particles, the zs, and that they are arranged table-wise. Suppose you also believe that those very zs are simultaneously arranged hunk-of-wood-wise.

Now, you also believe that, if there are tables, then they are fully grounded in things arranged table-wise. And if there are hunks of wood, they are fully grounded in things arranged hunk-wise. You also accept OIT. So you should postulate both a table and a hunk of wood (see Section 2).

Indeed, you should also postulate an inside-table, an object that is also composed of those same zs but that cannot survive being brought outside. While you're at it, you should postulate an inside-the-living-room table, an exists-for-one-second table, an exists-only-while-being-looked-at table, and so on. After all, each of these objects would be ontologically innocent to the zs and the way the zs are currently arranged. 
Of course, the table and hunk of wood have different qualitative properties. The table, but not the hunk of wood, can survive the loss of one of its legs. The inside-table and each of its strange coincident cousins also differ qualitatively from each of the many objects with which they coincide. So OIT has led you to postulate a plenitude of numerically distinct but mereologically coincident composite objects. ${ }^{15}$

More importantly, note that the zs at least partially ground the table, the hunk of wood, the inside-table, the exists-for-one-second table, and so on, respectively. Surely it is not the case that, for every one of these coincident objects $\mathrm{K}$, there is some unique multi-grade relation $\mathrm{R}$ holding among the zs such that the zs' being R serves as a unique full ground for the K object. Or, at least, no advocate of OIT should postulate each of these unique multi-grade relations.

To see this, note the zs are microphysical particles. Presumably, then, if there were a unique multi-grade relation $\mathrm{R}$ corresponding to each kind of coincident object, each such relation would either be a unique fundamental relation or ultimately grounded in a unique fundamental relation. As a result, postulating any one of these coincident objects would require postulating an additional fundamental fact about the zs, namely, that the zs bear the relevant fundamental relation to one another. However, given OIT, commitment to a grounded entity is not accompanied by a new commitment to one or more fundamental facts (Section 3).

Therefore, the defender of OIT should accept that, for at least two of the distinct coincident objects she has postulated, $\mathrm{O}$ and $\mathrm{O}^{*}$, there is some multi-grade relation $\mathrm{R}$ such that the zs bearing $\mathrm{R}$ to one another fully grounds both $\mathrm{O}$ and $\mathrm{O}^{*}$. That is, the defender of OIT should believe that $\mathrm{O}$

\footnotetext{
${ }^{15}$ Note that defenders of OIT, unlike those who believe that composite objects are "additions to being" over and above their composing parts, cannot solve the problems of mereological coincidence by eliminating either one or all of the alleged coinciding objects. See Merricks [2001: 38-47] on the eliminativist strategy. On material plenitude, see Bennett [2004], Hawthorne [2006], Inman [2014], Sosa [1987], and Thomasson [2007: 170_173].
} 
and $\mathrm{O}^{*}$ are groundmates. Indeed, most principled defender of OIT should believe that every material object has many, many coincident groundmates (see Section 6).

\section{Innocence and Groundmates}

Here is the fourth premise:

(4) If PFT is true then there are no groundmates.

I will defend Premise 4's contrapositive: if there are groundmates then PFT is false.

We have seen three kinds of grounded entities with groundmates: sets, composite objects, and higher-level worldly facts (Section 4.1-3). Any grounded entity of any of these three kinds and any of its groundmates will both violate PFT. As an illustration, consider $\{$ Socrates $\}$ and its groundmate, $\{\{$ Socrates $\}\}$.

\{Socrates $\}$ has the following qualitative property: having a human member. $\{$ Socrates $\}$ is fully grounded in Socrates. Socrates has various qualitative properties, H1...Hn. So PFT's antecedent is satisfied. Moreover, $\{\{$ Socrates $\}\}$ is also fully grounded in Socrates. And Socrates, being self-identical, has properties H1...Hn. Nevertheless, $\{\{$ Socrates $\}\}$ lacks the qualitative property of having a human member. So PFT's consequent is violated. Therefore, PFT is false.

More generally, every grounded entity with a groundmate qualitatively differs in some way from its groundmate. So every grounded entity with a groundmate violates PFT. ${ }^{16}$ Therefore, if there are groundmates then the PFT is false. By contraposition, Premise 4 is true.

\footnotetext{
${ }^{16}$ Suppose that, possibly, some grounded entity has a qualitatively indiscernible but numerically distinct groundmate. In that case, not every possible groundmate pair violates PFT. However, no defender of OIT can allow for the possibility of qualitatively indiscernible groundmates. For if qualitatively indiscernible groundmates were possible, then OIT would be false. To see this, suppose that two numerically distinct grounded entities $\mathrm{x}$ and y are qualitatively
} 
I have now defended each of the substantive premises of the following reductio argument against OIT:

(1) OIT is true (assume for reductio).

(2) If OIT is true then the PFT is true.

(3) If OIT is true then there are groundmates.

(4) If the PFT is true there are no groundmates.

(5) Therefore, there are groundmates $(1,3)$.

(6) Therefore, there are no groundmates $(1,2,4)$.

(7) Therefore, there are groundmates and there are no groundmates $(5,6)$

(8) Therefore, OIT is false $(1,7)$.

\section{Three Surprising Options}

That OIT is false, all by itself, tells us very little about the relationship between a grounded entity and its full grounds. Neither does OIT's falsity alone imply anything about which kinds of grounded entities there are. Indeed, perhaps there are no grounded entities whatsoever. Fortunately, the arguments of Sections 3, 4, and 5 leave us with only three options.

Consider the kinds of paradigmatically grounded entities we encountered in Section 4sets, facts, and composite objects. Option 1: entities of at least one of these three kinds exists and are grounded entities. Option 2: entities of at least one of these three kinds exists and are

indiscernible and one another's groundmates. Now, $x$ is not identical with $y$. Yet $y$ is identical with $y$. Consider the fact that $\mathrm{x}$ is not identical with $\mathrm{y}$. That fact is either fundamental or it is metaphysically explained in terms of some fundamental, non-qualitative fact about x. Either way, there is some fundamental fact about a grounded entity. So OIT is false (Section 3). Thanks to an anonymous referee, Ross Cameron, and Dan Korman for discussion. 
fundamental entities. Option 3: none of these kinds of entities exist. Each of these three options is surprising in its own way.

Option 1 says that there are either grounded sets, grounded composites, grounded higherlevel facts, or all three. That much is perfectly orthodox. However, Option 1 does have a heterodox implication.

Consider a familiar principle:

Purity: there are no fundamental facts about any grounded entity.

Purity is popular among grounding's defenders (see deRosset [2013] and Bennett [2017: ch. 7]). Indeed, acceptance of Purity is so deeply entrenched that there is a veritable cottage industry devoted to one of Purity's puzzling implications, namely, that every fact about what grounds what is itself grounded (see Bennett [2017: ch.7], Dasgupta [2014], deRosset [2013], and Sider [2020]).

However, if Option 1 is true then Purity is false. For if there are either grounded sets or grounded composites or grounded facts, then there are groundmates (Section 4.1-3). Moreover, if there are groundmates then PFT is false (Section 5). And if PFT is false then so is Purity (Section 3). ${ }^{17}$ Therefore, if Option 1 is true then Purity is false.

Indeed, the arguments of Section 4 show that every grounded set, grounded composite object, or grounded higher-level fact has at least one groundmate. Thus, every grounded entity of those three kinds violates Purity. Moreover, sets, composite objects, and facts are three of the most

\footnotetext{
${ }^{17}$ Section 3's argument relied on a well-foundedness constraint on metaphysical explanation, WF. Thus, a defender of Option 1 desperate to preserve the truth of Purity might opt to reject WF instead. In doing so, of course, she would merely be trading out one surprising consequence of Option 1 for another.
} 
paradigmatic cases of grounding. So, if Option 1 is true, violations of Purity are not isolated to a few odd grounded entities. Rather, violations of Purity are commonplace. ${ }^{18}$

Recognition of the sheer ubiquity of fundamental facts about grounded entities ought to influence the methodology of non-fundamental metaphysics. As a case study, consider the socalled "grounding problem" for the statue and the lump of clay (see Merricks [2001] and Olson [2001]). The statue and the lump mereologically coincide and are situated in the same surroundings. Nevertheless, they have different "sortalish" properties (Bennett [2004]). The grounding problem concludes that the statue and lump's sortalish differences must be metaphysically inexplicable, fundamental, or brute.

Many philosophers take the grounding problem's conclusion, all by itself, as a reason to deny that the state exists, or to deny that the lump exists, or both. For, so these philosophers assume, there cannot be brute or fundamental sortalish facts about such entities as the statue and the lump of clay. For surely the qualitative facts about composite material objects are all ultimately grounded in the facts about the physical properties of interrelations among their microphysical parts.

However, if Option 1 is true, then the statue and the lump of clay are groundmates (see Section 4.3). Moreover, if Option 1 is true, then there are brute facts about every kind of groundmate pair, including set-set groundmates, fact-fact groundmates, and so on. Thus, defenders of the grounding problem must articulate why the alleged brute sortalish facts about the statue and the lump render those objects uniquely objectionable.

\footnotetext{
18 According to Modal Recombinability (MR), if fact $\mathrm{x}$ is fundamental and fact $\mathrm{y}$ is fundamental and $\mathrm{x}$ and $\mathrm{y}$ are distinct then, possibly, x obtains and y does not and vice-versa. Karen Bennett [2017: ch. 7] argues that Purity follows from MR. If she is correct, then defenders of Option 1 must deny MR. Those wedded to MR, on the other hand, must reject Option 1 in favor of the "flatworldism" of Options 2 or 3 . Thanks to an anonymous referee for helpful discussion here.
} 
More generally, if Option 1 is true, then the mere fact that some metaphysical theory implies that there are brute or fundamental facts about entities at reality's non-fundamental levels is not, all by itself, an objection to that theory. Bruteness-based objections to such theories must also draw a principled distinction between more objectionable brute facts and less objectionable brute facts. In future work, I plan to develop exactly such a distinction. ${ }^{19}$

Option 2 says that either sets, higher-level facts, composite objects, or all three types of entities exist, but that no entity of any of these types is grounded. So Option 2 implies that entities of these three types are all fundamental. However, sets, higher-level facts, and composite material objects are paradigm cases of grounded entities - surely if anything is grounded, one or more of these types of entities is. Thus, on the most principled version of Option 2, no entity whatsoever is grounded. Everything is fundamental.

Karen Bennett [2011: 2-3] calls the view that everything is fundamental "flatworldism." She is not the view's biggest fan:

I have no knockdown argument against the claim that the world is flat. But every fiber of my being cries out in protest... I have no real argument against it. I will simply say that flatworldism is, to borrow a colorful word from a friend, "crazypants".

One might wonder whether, at the end of the day, there is a real metaphysical difference between Option 1 and Option 2. After all, most of grounding's advocates accept the Purity constraint on grounding. So what is the metaphysical difference between a fundamental entity and a grounded entity about which there is at least one fundamental fact? Does this merely reflect a

\footnotetext{
${ }^{19}$ Some defenders of coincident material objects, eg. Saenz [2015] and Sutton [2012], solve the grounding problem by claiming that the statue and the lump are not, after all, groundmates. Perhaps they are right. My only point here is that if the statue and the lump are indeed groundmates, then anyone who thinks the grounding problem is a good reason to eliminate the statue and the lump should also, for analogous reasons, eliminate every other kind of groundmate pair - fact-fact groundmate pairs, set-set groundmate pairs, etc.
} 
difference in how we choose to use the words "grounded" and "fundamental"? I hope to address this question in future work.

Option 3 says that sets, higher-level facts, and composite material objects do not exist at all. On Option 3, then, reality is significantly sparser than it intuitively seems to be. Indeed, perhaps the most principled version of Option 3 is a wholesale eliminativism about the non-fundamental. Like Option 2, Option 3 is a a version of flatworldism. However, while Option 2's flat world is abundantly populated, Option 3's flat world is a desert landscape. ${ }^{20}$

${ }^{20} \mathrm{I}$ am grateful to anonymous referees and an Associate Editor at AJP for helpful comments and suggestions. The paper also received helpful feedback from audiences at the 72nd Annual Mountain-Plains Philosophy Conference. My commentator, Bradley Rettler, gave excellent comments. Mike Rea and Sam Newlands provided helpful suggestions about the paper's structure and argument at University of Notre Dame's Center for Philosophy of Religion paper workshop. I also had helpful discussions about the paper's main argument with Elizabeth Barnes, Ross Cameron, Dan Korman, Noel Saënz, and Peter Tan, all of whom offered challenging objections that greatly improved the paper. Thanks to Peter Tan for encouraging me to pursue this idea. I owe the biggest debt to my advisor, Trenton Merricks. Trenton gave me extensive feedback on countless drafts of the paper. I learned how to write a good philosophy paper by revising and re-revising the paper in light of his objections and advice. 


\section{Bibliography}

Audi, Paul 2012. A Clarification and Defense of the Notion of Grounding, in Metaphysical Grounding: Understanding the Structure of Reality, ed. Fabrice Correia \& Benjamin Schnieder, Cambridge, UK: Cambridge University Press: 101-121.

Barker, Jonathan 2019. Debunking Arguments and Metaphysical Laws, Philosophical Studies.

Baker, L.R. 1997. Why Constitution is Not Identity, Journal of Philosophy 94/12: 599-621.

Bennett, Karen 2017. Making Things Up. Oxford: Oxford University Press.

Bennett, Karen 2011. By Our Bootstraps, Philosophical Perspectives, 25/1: 27-41.

Bennett, Karen 2004. Spatio-Temporal Coincidence and the Grounding Problem. Philosophical Studies 118/3:339-371.

Cameron, Ross P. 2014. Parts Generate the Whole, But They are Not Identical to It, in Composition as Identity, ed. A.J. Cotnoir and Donald Baxter, Oxford, UK: Oxford University Press.

Cameron, Ross P. 2008. Truthmakers and Ontological Commitment. Philosophical Studies 140/1:1 - 18.

Correia, Fabrice \& Schnieder 2012. in Correia \& Schnieder eds., 1-36.

Dasgupta, Shamik 2014. The Possibility of Physicalism, Journal of Philosophy 111/10:557-592. deRosset, Louis 2010. Getting Priority Straight. Philosophical Studies 149/1: 113-97.

deRosset, Louis 2013. Grounding Explanations, Philosophers' Imprint 13.

Dixon, T. Scott 2016. What Is the Well-Foundedness of Grounding?, Mind 125/498:439-468.

Fine, Kit 2012. Guide to Ground, in Correia \& Schnieder (ed), Cambridge University Press: 37 80.

Fine, Kit 2009. The Question of Ontology, in Metametaphysics, ed. Chalmers, Manley \& Wasserman, Oxford, UK: Oxford University Press. pp. 157--177. 
Fine, Kit 2001. The Question of Realism, Philosophers' Imprint 1/1:1-30.

Fine, Kit 1995. Ontological Dependence, Proceedings of the Aristotelian Society 95: 269 - 290.

Hawthorne, John 2006. Metaphysical Essays, Oxford, UK: Oxford University Press.

Horgan, T. \& Potrč 2012. Existence Monism Trumps Priority Monism, in Spinoza on Monism, Goff (ed.), Palgrave Macmillan: 51--76.

Inman, Ross 2014. Neo-Aristotelian Plenitude, Philosophical Studies 168/3:583-597.

Jenkins, C. S. 2011. Is Metaphysical Dependence Irreflexive?, The Monist 94/2: 267-276.

Korman, Daniel Z. 2010. Strange Kinds, Familiar Kinds, and the Charge of Arbitrariness, Oxford Studies in Metaphysics: 119-144.

Koslicki, Kathrin 2012. Varieties of Ontological Dependence, in Correia \& Schnieder (eds.). $186-213$.

Merricks, Trenton 2001. Objects and Persons, Oxford: Oxford University Press.

Nolan, Daniel 1997. Quantitative Parsimony, British Journal for the Philosophy of Science, 48/ 3:329-343.

Olson, Eric T. 2001. Material Coincidence and the Indiscernibility Problem. Philosophical Quarterly, 51/204: 337-355.

Rosen, Gideon 2010. Metaphysical Dependence: Grounding and Reduction, in Modality: Metaphysics, Logic, and Epistemology, B. Hale \& A. Hoffmann (ed.), Oxford: Oxford University Press: 109--36.

Saenz, Noël B. Manuscript. The Disciplining of Grounding.

Saenz, Noël B. 2015. A Grounding Solution to the Grounding Problem, Philosophical Studies, 172/8: 2193-2214.

Schaffer, Jonathan 2016. Grounding in the Image of Causation, Philosophical Studies, 173/1: 49- 
100.

Schaffer, Jonathan 2014. What Not to Multiply Without Necessity, Australasian Journal of Philosophy, 93/ 4: 644-664.

Schaffer, Jonathan 2012. Why the World Has Parts: Reply to Horgan and Potrc, in Goff (ed.), Spinoza on Monism.

Schaffer, Jonathan 2010a. Monism: The Priority of the Whole, Philosophical Review, 119/1:3176.

Schaffer, Jonathan 2010b. The Internal Relatedness of All Things, Mind 119/474: 341 - 376.

Schaffer, Jonathan 2009. On What Grounds What, in Manley, Chalmers \& Wasserman (eds.): 347383.

Skiles, Alexander 2015. Against Grounding Necessitarianism, Erkenntnis 80/4:717-751.

Sider, Theodore 2020. Ground Grounded, Philosophical Studies, 177/3: 747—767.

Sider, Theodore 2011. Writing the Book of the World, Oxford: Oxford University Press.

Sosa, Ernest 1987. Subjects Among Other Things, Philosophical Perspectives, 1: 155-187.

Sutton, C. S. 2012. Colocated Objects, Tally-Ho: A Solution to the Grounding Problem, Mind 121/483:703-730.

Thomasson, Amie L. 2007. Ordinary Objects, Oxford: Oxford University Press.

Turner, Jason 2016. Curbing Enthusiasm About Grounding, Philosophical Perspectives, 30/1:366396. 